\title{
MRS Selects Outstanding Symposium Papers
}

In recognizing proceedings as an important and integral part of Materials Research Society meetings, the chairs of the 2004 MRS Fall Meeting implemented an awards program for the best symposium manuscripts. The chairs-Shefford P. Baker (Cornell University), Julia Hsu (Sandia National Laboratories), Bethanie J.H. Stadler (University of Minnesota), and Richard Vaia (Air Force Research Laboratory)-requested that symposium organizers select the award recipients based solely on the written manuscripts and not on the oral or poster presentations.

Nominations for best papers were made based on both technical content and manuscript quality. No more than $5 \%$ from the accepted manuscripts in each proceedings volume could be nominated (Ribbon Award). The best manuscript from among the nominations in each proceedings volume were selected by the organizers to receive the Trophy Award for Best Symposium Proceedings Paper Award. The contact authors received a $\$ 100$ award in addition to an invitation from the Journal of Materials Research to submit an article based on their papers.

Following is a partial list of award recipients. Papers can be accessed at www.mrs.org/publications / epubs / proceedings/fall2004.
Progress in Compound Semiconductor Materials IV-Electronic and Optoelectronic Applications

(Symposium B)

(Proceedings Volume 829)

Trophy Award (Best Paper): B8.7 Towards $p$-Type Doping of ZnO by Ion Implantation

V.A. Coleman, H.H. Tan, C. Jagadish of the Australian National University; S.O. Kucheyev of Lawrence Livermore National Laboratory; M.R. Phillips of the University of Technology Sydney; and J. Zou of the University of Queenland, St. Lucia.

Ribbon Award (Best Paper Nomination): B1.4 Intersubband Transitions in $\mathrm{In}_{0.3} \mathrm{Ga}_{0.7} \mathrm{As} / \mathrm{GaAs}$ Multiple Quantum Dots of Varying Dot-Sizes

Y.C. Chua, J. Liang, B.S. Passmore, E.A. DeCuir, M.O. Manasreh, Z. Wang, and G.J. Salamo of the University of Arkansas;

B1.8 Virtual Fabrication of Small GaAs/P and In-As/P Clusters with PreDesigned Electronic Pattern Structure L.A. Pozhar of Western Kentucky University, and A.T. Yeates, F. Szmulowicz, and W.C. Mitchel of the Air Force

Research Laboratory;

B2.23 Defect Structures in Undoped and Doped ZnO Films Studied by Solid State Diffusion

H. Ryoken of the National Institute for Materials Science, Japan/Kyushu University, and I. Sakaguchi, T. Ohgaki, N. Ohashi, Y. Adachi, and H. Haneda of the National Institute for Materials Science, Japan;

B2.28 Raman Spectroscopy of V and Co Doped ZnO Ceramics and Thin Films K. Samanta, N. Awasthi,

B. Sundarakannan, P. Bhattacharya, and R.S. Katiyar of the University of Puerto Rico; and

B5.9 Dispersion Engineering of ThreeDimensional Silicon Photonic Crystals: Fabrication and Applications
S. Venkataraman, G. Schneider, J. Murakowski, S. Shi, and D.W. Prather of the University of Delaware.

Materials and Processes for Nonvolatile Memories

(Symposium D)

(Proceedings Volume 830)

Trophy Award (Best Paper):

D7.5 Experimental Observation of

Non-Volatile Charge Injection and

Molecular Redox in Fullerenes $\mathrm{C}_{60}$ and

$\mathrm{C}_{70}$ in an EEPROM-Type Device

U. Ganguly, C. Lee, and E.C. Kan of

Cornell University.

Ribbon Award (Best Paper Nomination):

D1.4 Backside Storage Non-Volatile

Memories: Ultra-Thin Silicon Layer on

a Complex Thin Film Structure

H. Silva and S. Tiwari of Cornell

University; and

D7.2 Organic Memory Devices Using

$\mathrm{C}_{60}$ and Insulating Polymer

A. Kanwal, S. Paul, and M. Chhowalla of

Rutgers University.

Group-IV Semiconductor

Nanostructures

(Symposium F)

(Proceedings Volume 832)

Trophy Award (Best Paper):

F5.1 Progress in the Growth and

Characterization of Ge Quantum Dots and Islands

J.-M. Baribeau, N.L. Rowell, and D.J.

Lockwood of the National Research

Council Canada.

Ribbon Award (Best Paper Nomination):

F1.1 Silicon-Based Integrated Optics:

Waveguide Technology to

Microphotonics

S. Janz, A. Bogdanov, P. Cheben, A. Delâge,

B. Lamontagne, M.-J. Picard, D.-X. Xu,

K.P. Yap, and W.N. Ye of the National

Research Council Canada;

F8.9 Enhancing the Sound Pressure of Thermally Induced Ultrasonic Emitter
Based on Nanocrystalline Porous Silicon K. Tsubaki and T. Komoda of Matsushita Electric Works, Osaka; and N. Koshida of Tokyo University of A\&T; and

F9.10 Fabrication and Electrical Characterization of Silicon Nanowire Arrays S.M. Dilts, A. Mohmmad, K.-K. Lew, J.M. Redwing, and S.E. Mohney of the Pennsylvania State University;

Materials, Integration and Packaging Issues for High-Frequency Devices II (Symposium G)

(Proceedings Volume 833)

Trophy Award (Best Paper):

G1.10 AC Loss Modeling in

$\mathrm{Ba}_{0.5} \mathrm{Sr}_{0.5} \mathrm{TiO}_{3}$ Using Dielectric

Relaxation

N.K. Pervez, J. Lu, S. Stemmer, and

R.A. York of the University of California, Santa Barbara.

Ribbon Award (Best Paper Nomination): G2.2 Pulsed DC Sputtered Aluminum Nitride: A Novel Approach to Control Stress and C-Axis Orientation P. Soussan, J. D'Haen, E. Beyne, and H.A.C. Tilmans of IMEC; K. O'Donnell of NEXX Systems, Mass.; and G. Vanhoyland of Limburgs Universitair Centrum, Belgium;

G2.8 Precision Measurement of Low Loss Window Materials

J. Dutta and C. Jones of North Carolina Central University;

G3.13 A Novel Copper Damascene Technique for Power Loaded SAW Structures

S.B. Menzel, D. Reitz, H. Wendrock, H. Schmidt, M. Weihnacht, and K. Wetzig of Leibniz Institute for Solid State and Materials Research, Dresden; and M. Albert and J.W. Bartha of Dresden University of Technology;

G5.1 Recent Advances in Microwave Applications of Thin Ferroelectric Films at the NASA Glenn Research Center R.R. Romanofsky and F.A. Miranda of 
NASA Glenn Research Center; F.W. Van Keuls of Ohio Aerospace Institute; and M.D. Valerio of Ohio Northern

University; and

G5.2 Stroboscopic X-Ray Diffraction

Measurements of Sub-ns Domain

Dynamics in Ferroelectric Films

E. Zolotoyabko of Technion-Israel Institute ofTechnology; and J.P. Quintana,

D.J. Towner, and B.W. Wessels of

Northwestern University.

Fabrication and New Applications of Nanomagnetic Structures

(Symposium I)

(Proceedings Volume 853E)

Trophy Award (Best Paper):

I9.1 Magnetoresistive Sensors and

Magnetic Nanoparticles for

Biotechnology

G. Reiss, H. Brueckl, A. Huetten,

J. Schotter, M. Brzeska, D. Sudfeld,

A. Becker, P.B. Kamp, A. Puehler, and

P. Jutzi of the University of Bielefeld.

Ribbon Award (Best Paper Nomination):

I6.7 Room-Temperature

Magnetoresistance of One-

Dimensional Magnetite $\left(\mathrm{Fe}_{3} \mathrm{O}_{4}\right)$

Nanostructures

Z. Liu, D. Zhang, and C. Zhou of the

University of Southern California.

\section{Magneto-Optical Materials for}

Photonics and Recording

(Symposium J)

(Proceedings Volume 834)

Trophy Award (Best Paper):

(J6.3) Novel Magneto-Optic Layers

Based on Semiconductor

Nanostructures for Kerr Microscopy

C. Gourdon and V. Jeudy of Universités

Paris, G. Karczewski of the Polish

Academy of Sciences, R. André of

Université Joseph Fourier-Grenoble I,

and E.L. Ivchenko of the Russian

Academy of Sciences.

Ribbon Award (Best Paper Nomination):

(J4.7) Fabrication of a TE Mode

InGaAsP Active Waveguide Optical

Isolator Based on the Nonreciprocal

Loss Shift

H. Shimizu and Y. Nakano of the

University of Tokyo.

\section{Solid-State lonics}

(Symposium K)

(Proceedings Volume 835)

Trophy Award (Best Paper):

(K1.2) Sodium Ion Conduction in Plastic Phases: Dynamic Coupling of Cations and Anions in the Picosecond Range

D. Wilmer and H. Feldmann of Münster
University, Münster; R.E. Lechner of Hahn-Meitner-Institut of Berlin; and J. Combet of Institut Laue-Langevin, Grenoble.

Ribbon Award (Best Paper Nomination): (K7.4) Nanostructured PEFC Electrode Catalysts Prepared via In Situ Colloidal Impregnation

K. Sasaki, K. Shinya, S. Tanaka,

Y. Kawazoe, T. Kuroki, K. Takata,

H. Kusaba, and Y. Teraoka of Kyushu

University, Japan; and

(K10.3) Improved Composite Electrode and Lithium Battery Performance From Smart Use of the Polymers and Their Properties

V. Gaudefroy, D. Guy, B. Lestriez, and

D. Guyomard of Université de Nantes,

France; and R. Bouchet of Université de Marseille, France.

Scanning Probe and Other Novel

Microscopies of Local Phenomena in Nanostructured Materials

(Symposium O)

(Proceedings Volume 838E),

Trophy Award (Best Paper):

(O5.2) Optical Near-Field Enhancement

Around Lithographic Metallic

Nanostructures Using an Azodye

Polymer: Direct Observation and

Realization of Sub-Wavelength

Complex Structures

C. Hubert, A. Rumyantseva, G. Lérondel,

J. Grand, S. Kostcheev, L. Billot, A. Vial,

R. Bachelot, and P. Royer of Université de

Technologie de Troyes, France; G. Chang of Argonne National Laboratory/

Northwestern University; S.K. Gray and

G.P. Wiederrecht of Argonne National

Laboratory; and G.C. Schatz of

Northwestern University.

Ribbon Award (Best Paper Nomination): (O1.2) Biaxial Strain Induced Electrical Inhomogenities and Phase Separation in the Ferromagnetic Metallic Phase in Thin Films of $\mathrm{La}_{0.7} \mathrm{Ca}_{0.3} \mathrm{MnO}_{3}: \mathrm{A}$ Scanning Tunneling Potentiometry/ Spectroscopy Study

M. Paranjape, J. Mitra, and

A.K. Raychaudhuri of the Indian Institute of Science, Bangalore; and N.D. Mathur and M.G. Blamire of the University of Cambridge; and

(O11.1) Novel Dynamic Scanning Microscope Probe and Its Application to Local Electrical Measurement in an Ion Sensitive Field Effect Transistor

T. Akiyama, K. Suter, N.F. de Rooij, and U. Staufer of the University of

Neuchâtel, Switzerland.
Neutron and X-Ray Scattering as Probes of Multiscale Phenomena (Symposium Q)

(Proceedings Volume 840)

Trophy Award (Best Paper):

(Q7.1) 2D and 3D X-Ray Structural

Microscopy Using Submicron-

Resolution Laue Microdiffraction

J.D. Budai, W. Yang, B.C. Larson,

J.Z. Tischler, W. Liu, and G.E. Ice of Oak

Ridge National Laboratory.

Ribbon Award (Best Paper Nomination): (Q3.3) Large-Scale Morphology of Dispersed Layered Silicates

D.W. Schaefer of the University of Cincinnati/Chinese Academy of Science, R.S. Justice of the University of Cincinnati, H. Koerner of the University of Dayton Research Institute, R. Vaia of the Air Force Research Laboratory, C. Zhao and M. Yang of the Chinese Academy of Sciences, and J. Vale of Givaudan Flavors Corp., Cincinnati; and (Q6.10) $\mathrm{CoPt}_{3}$ Nanoparticles Adsorbed on $\mathrm{SiO}_{2}$ : A GISAXS and SEM Study J.I. Flege, T. Schmidt, G. Alexe, T. Clausen, and J. Falta of the University of Bremen, Germany; S. Bernstorff of Sincrotrone Trieste, Italy; and I. Randjelovic, V. Aleksandrovic, A. Kornowski, and $\mathrm{H}$. Weller of the University of Hamburg, Germany.

\section{Fundamentals of Nanoindentation} and Nanotribology III

(Symposium R)

(Proceedings Volume 841)

Trophy Award (Best Paper):

(R5.5) Indentation Creep and

Relaxation Measurements of Polymers M.R. VanLandingham of the U.S. Army Research Laboratory, Aberdeen Proving Ground, Md.; and P.L. Drzal and C.C. White of the National Institute of Standards and Technology.

Ribbon Award (Best Paper Nomination): (R7.4) Multiscale Modeling of Two Dimensional Rough Surface Contacts B. Luan, S. Hyun, and M.O. Robbins of the Johns Hopkins University, and N. Bernstein of the Naval Research Laboratory, Washington, D.C.;

(R9.7) Spherical Load Indentation in Submicron NiTiCu Shape Memory Thin Films

R. Hassdorf, J. Feydt, S. Thienhaus, L. Buforn, O. Pykhteev, N. Botkin, and M. Moske of the Center of Advanced European Studies and Research, Bonn; N. Conté of CSM Instruments SA, Peseux, Switzerland; and M. Kru凶ík of the Center of Advanced European 
Studies and Research, Bonn/Academy of Sciences, Prague; and

(R10.4/T6.4) Cross-Sectional TEM Studies of Indentation-Induced Phase Transformations in Si: Indenter Angle Effects

S. Wen and J.-I. Jang of the University of Tennessee, J. Bentley of Oak Ridge National Laboratory, and G.M. Pharr of the University of Tennessee/Oak Ridge National Laboratory.

\section{Surface Engineering-Fundamentals} and Applications

(Symposium T)

(Proceedings Volume 843)

Trophy Award (Best Paper): (T1.6) Nanocomposite TiC/a-C Coatings: Structure and Properties J.Th.M. De Hosson, Y. Pei, and D. Galvan of the University of Groningen, the Netherlands; and A. Cavaleiro of Universidade de Coimbra Pinhal de Marrocos, Portugal.

Ribbon Award (Best Paper Nomination): (T4.10) UV Raman Scattering Analysis of Indented and Machined $6 \mathrm{H}-\mathrm{SiC}$ and B-Si ${ }_{3} \mathbf{N}_{4}$ Surfaces

J.J.H. Walter, M. Liang, and R.J. Nemanich of North Carolina State University; X.-B. Chen and L. Bergman of the University of Idaho; J.-I. Jang of the University of Tennessee; J.A. Patten of Western Michigan University; and G.M. Pharr of the University of Tennessee/ Oak Ridge National Laboratory.

(T6.4/R10.4) Cross-Sectional TEM Studies of Indentation-Induced Phase Transformations in Si: Indenter Angle Effects S. Wen and J.-I. Jang of the University of Tennessee, J. Bentley of Oak Ridge National Laboratory, and G.M. Pharr of the University of Tennessee/Oak Ridge National Laboratory.

\section{Stability of Thin Films and}

\section{Nanostructures}

(Symposium U)

(Proceedings Volume 854E)

Trophy Award (Best Paper):

(U6.6) In Situ TEM Observations of Grain Growth in Nanograined Thin Films

K. Hattar, J. Gregg, J. Han, T.Saif, and

I.M. Robertson of the University of

Illinois, Urbana-Champaign.

Ribbon Award (Best Paper Nomination): (U7.4) Thermal Grooving in Single versus Multilayer Thin Films P.M. Anderson and J. Wang of the Ohio State University, and S. Narayanaswamy of Rockwell Science Center, Thousand Oaks, Calif.
Mechanical Properties of Bio-Inspired and Biological Materials

(Symposium Y)

(Proceedings Volume 844)

Trophy Award (Best Paper):

(Y5.3) Uniaxial and Biaxial Mechanical Behavior of Human Amnion

M.L. Oyen, T. Stylianopoulos, and

V.H. Barocas of the University of

Minnesota; S.E. Calvin of the University

of Minnesota/Minnesota Perinatal

Physicians / Allina Health System; and

R.F. Cook of Minneapolis, Minn.

Ribbon Award (Best Paper Nomination):

(Y6.11) Nanoscale Measurements of

Water Loss During Desiccation of

Biological Cell Suspensions

S. Mittal and R.V. Devireddy of

Louisiana State University;

(Y7.6) A Model for the Increased Elastic Compliance in Human Cancer Cells

C. Mohrdieck and E. Arzt of Max Planck Institute for Metals Research; and

(Y7.8) Continuous Force-Displacement

Relationships for the Human Red

Blood Cell at Different Erythrocytic

Developmental Stages of Plasmodium

Falciparum Malaria Parasite

J.P. Mills, M. Dao, and S. Suresh of the

Massachusetts Institute of Technology; and L. Qie, K.S.W. Tan, and C.T. Lim of the National University of Singapore.

\section{Nanoscale Materials Science in}

Biology and Medicine

(Symposium AA)

(Proceedings Volume 845)

Trophy Award (Best Paper):

(AA1.8) Competitive Guidance Cues

Affect Fibroblast Cell Alignment:

Electric Fields vs. Contact Guidance

I.R. Gibson and C.D. McCaig of the

University of Aberdeen, U.K.

Ribbon Award (Best Paper Nomination): (AA2.9) A Novel Polymer-Synthesized Ceramic Composite Based System for Bone Repair: Osteoblast Growth on Scaffolds with Varied Calcium Phosphate Content

Y.M. Khan of Drexel University; D.S. Katti of the Indian Institute of Technology, Kanpur; and C.T. Laurencin of the University of Virginia;

(AA4.3) Microfabricated 3D Scaffolds for Tissue Engineering Applications A. Mata, A.J. Fleischman, and S. Roy of the Cleveland Clinic Foundation; and

(AA6.9) Formation of Titania

Submicron-Scale Rod Arrays on

Titanium Substrate and In Vitro Biocompatibility
S. Hayakawa, Y. Liu, K. Okamoto, K. Tsuru, and A. Osaka of Okayama University, Japan.

\section{Organic and Nanocomposite Optical} Materials

(Symposium DD)

(Proceedings Volume 846)

Trophy Award (Best Paper):

(DD8.2) Self-Assembled

Oligonucleotide Semiconductor Conjugated to GaN Nanostructures for Biophotonic Applications

A. Neogi, J. Li, P.B. Neogi, B. Gorman, and T. Golding of the University of North Texas; A. Sarkar of the Michigan Molecular Institute; and H. Morkoc of Virginia Commonwealth University.

Ribbon Award (Best Paper Nomination): (DD1.2) Spectral Profiles of TwoPhoton Absorption: Coherent Versus Two-Step Two-Photon Absorption S. Polyutov, I. Minkov, F. Gel'mukhanov, and H. Agren of the Royal Institute of Technology, Sweden; K. Kamada of AIST, Japan; and A. Baev of the State University of New York, Buffalo;

(DD4.4) Novel Iridium Complexes With Polymer Side-Chains

E. Holder, V. Marin, E. Tekin,

D. Kozodaev, M.A.R. Meier,

B.G.G. Lohmeijer, and U.S. Schubert of Eindhoven University of Technology and Dutch Polymer Institute; and

(DD10.7) Fabrication of Polydiacetylene Nanocrystals Deposited With Silver Nanoparticles for a Nonlinear Optical Material T. Onodera and H. Oikawa of the National Institute for Materials Science, Japan/JST/CREST; H. Kasai and H. Nakanishi of Tohoku University/JST/ CREST; and T. Sekiguchi of the National Institute for Materials Science, Japan.

\section{Kinetics-Driven Nanopatterning on Surfaces \\ (Symposium KK) \\ (Proceedings Volume 849) \\ Trophy Award (Best Paper):}

(KK4.3) Heteroepitaxial Self-Assembly of Higher-Complexity Structures by

Combining Growth Control With

Nanopatterning

J.A. Floro of Sandia National

Laboratories; and J.L. Gray, S. Atha, N. Singh, D. Elzey, and R. Hull of the University of Virginia.

Ribbon Award (Best Paper Nomination): (KK5.3) Kinetic Limitations in Two-and Three-Dimensional Growth K.L. Man, W.X. Tang, and M.S. Altman 
of Hong Kong University of Science and Technology and H. Huang of Rensselaer Polytechnic Institute.

Materials Issues in Solid Freeforming (Symposium LL)

(Proceedings Volume 860E)

Trophy Award (Best Paper):

(LL4.2) Use of Computational

Thermodynamics in Rapid Prototyping and Infiltrating Steel Parts

B.D. Kernan, E.M. Sachs, S. Allen, and

C. Sachs of the Massachusetts Institute

of Technology.

Ribbon Award (Best Paper Nomination):

(LL5.9) Production of Complex Nano-

Structures by Electro-Hydro-Dynamics

I.G. Loscertales of Universidad de

Málaga, Spain; A. Barrero of

Universidad de Sevilla, Spain; and

M. Márquez of Los Alamos National

Laboratory.

\section{Materials for Space Applications}

(Symposium NN)

(Proceedings Volume 851)

Trophy Award (Best Paper):

(NN8.7) Highly Stable Polymers Based on

Poly(m-carboranyl-siloxane) Elastomers

A.C. Swain, M. Patel, and J. J. Murphy of AWE, U.K

Ribbon Award (Best Paper Nomination): (NN3.3) Simulation of Absorbed Dose Distribution in Space Materials

B.A. Briskman of Karpov Institute of

Physical Chemistry, Russia;

(NN5.1) Screening of the Thermal
Endurance of Spacecraft Materials by Kinetic Modelling

M. Moser, S. Heltzel, C.O.A.

Semprimoschnig, and G. Garcia Martin of the European Space Agency/

European Space Research and

Technology Centre, the Netherlands;

(NN8.9) Volatile Evolution from

Polymer Materials Induced by

Irradiation with Accelerated $\mathrm{He}^{++}$Ions

J.J. Murphy and C.J. Wetteland of Los

Alamos National Laboratory;

(NN8.12) Raman Spectroscopy of

Graphitic Foams

E.B. Barros of Universidade Federal do Ceará, Brazil/Massachusetts Institute of Technology; N.S. Demir, G. Dresselhaus, and M.S. Dresselhaus of the Massachusetts Institute of Technology;

A.G. Souza Filho and J. Medes Filho of Universidade Federal do Ceará, Brazil; and A. Jorio of Universidade Federal de Minas Gerais, Brazil;

(NN9.7) Au Ion Induced Modification of $\mathrm{C}_{60}$ Thin Film Samples

N. Bajwa of Panjab University/Nuclear Science Center, New Delhi; A. Ingale of the Center for Advanced Technology, Indore/Universität Wuerzburg;

D.K. Avasthi, R. Kumar, and A. Tripathi of the Nuclear Science Center, New Delhi; K. Dharamvir and V.K. Jindal of Panjab University; and M. Schmitt and W. Kiefer of Universität Wuerzburg;

(NN9.9) Materials Testing Activities Within ESA in Support of Future Inner Solar System Missions
C.O.A. Semprimoschnig, S. Heltzel, and M. van Eesbeek of European Space

Agency, the Netherlands; and

(NN10.5) Developing Glassy Magnets from Simulated Composition of Moon/Mars Regolith for Exploration Applications

C.S. Ray and J. Rogers of NASA

Marshall Space Flight Center and

N. Ramachandran of BAE SYSTEMS

Analytical Solutions, Inc.

\section{Communicating Materials}

Science-Secondary Education for the 21st Century

(Symposium PP)

(Proceedings Volume 861E)

Trophy Award (Best Paper):

(PP3.4) Research Experiences for Teachers in Materials Science: A Case Study M.A. Strand of Southeast Community College, Milford, Neb.; S. Wignall of Seward High School, Seward, Neb.; and D.L. Leslie-Pelecky of the University of Nebraska, Lincoln.

Ribbon Award (Best Paper Nomination): (PP0.1) Employing Microfluidics in the Demonstration of Cell Encapsulation R.R. Ravgiala of Merrimack High School, Merrimack, N.H.; and

(PP5.5) Broadening Middle-School Students' Images of Science and Scientists

D.L. Leslie-Pelecky and G.A. Buck of the University of Nebraska, Lincoln; and

A. Zabawa of Lincoln Public Schools.

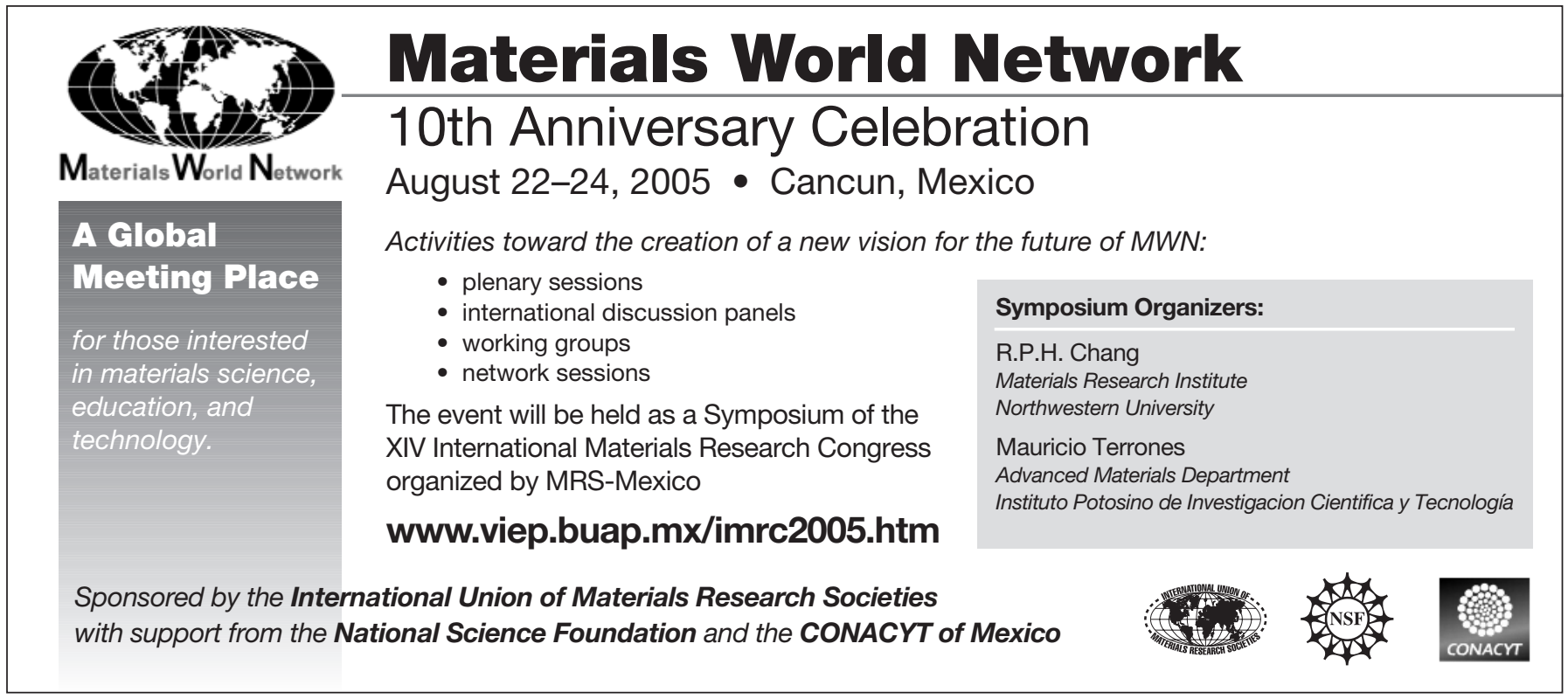

